\title{
MALAT1 Promotes Cell Apoptosis and Suppresses Cell Proliferation in Testicular Ischemia-Reperfusion Injury by Sponging MiR-214 to Modulate TRPV4 Expression
}

\author{
Wei Lia Jin-zhuo Ning ${ }^{b} \quad$ Fan Cheng $^{b} \quad$ Wei-min Yu ${ }^{b} \quad$ Ting Rao $^{b} \quad$ Yuan Ruan ${ }^{b}$ \\ Run Yuan ${ }^{b}$ Xiao-bin Zhang ${ }^{b}$ Yang Du ${ }^{b} \quad$ Cheng-cheng Xiao ${ }^{b}$ \\ aDepartment of Anesthesiology, Renmin Hospital of Wuhan University, Wuhan, Hubei Province, \\ ${ }^{b}$ Department of Urology, Renmin Hospital of Wuhan University, Wuhan, Hubei Province, P.R.China
}

\section{Key Words}

LncRNA MALAT1 • MiR-214 • TRPV4 • Testicular IRI • Apoptosis • Proliferation

\begin{abstract}
Background/Aims: Accumulating evidences has indicated that aberrant expression of long non-coding RNAs (IncRNAs) is tightly associated with the progression of ischemia-reperfusion injury (IRI). Previous studies have reported that IncRNA MALAT1 regulates cell apoptosis and proliferation in myocardial and cerebral IRI. However, the underlying mechanism of MALAT1 in testicular IRI has not been elucidated. Methods: The levels of of MALAT1, some related proteins and apoptosis in the testicular tissues were determined by quantitative real-time PCR, HE staining, immunohistochemistry, western blot and TUNEL assays. Relative expression of MALAT1, miR-214 and related proteins in cells were measured by western blot and quantitative real-time PCR. Cell viability and apoptosis were examined using MTT assay and flow cytometry. Results: In the present study, we found that MALAT1 was up-regulated in animal samples and GC-1 cells. The expression level of MALAT1 was positively related to cell apoptosis and negatively correlated with cell proliferation as testicular IRI progressed. In gain and loss of function assays, we confirmed that MALAT1 promotes cell apoptosis and suppresses cell proliferation in vitro and in vivo. Furthermore, we found that MALAT1 negatively regulates expression of miR-214 and promotes TRPV4 expression at the posttranscriptional level. Consequently, we investigated the correlation between MALAT1 and miR-214 and identified miR-214 as a direct target of MALAT1. In addition, we found that TRPV4 acted as a target of miR-214. Over-expression of miR-214 efficiently abrogated the up-regulation of TRPV4 induced by MALAT1, suggesting that MALAT1 positively regulates the expression of TRPV4 by sponging miR-214. Conclusion: In sum, our study indicated that the IncRNA MALAT1 promotes cell apoptosis and suppresses cell proliferation in testicular IRI via miR-214 and TRPV4.

W. Li and J.-Z. Ning contributed equally to this work.




\section{Cellular Physiology Cell Physiol Biochem 2018;46:802-814 \begin{tabular}{l|l|l|l} 
DOI: 10.1159/000488738 & (O 2018 The Author(s). Published by S. Karger AG, Basel
\end{tabular} Published online: April 06, 2018 www.karger.com/cpb \\ Li et al.: LncRNA MALAT1 in Testicular Ischemia-Reperfusion Injury}

\section{Introduction}

Testicular torsion is an acute urological emergency involving aberrant twisting of the spermatic cord and mostly affects young and adolescent males [1]. Since prolonged ischemia of the testis can lead to irreversible damage, prompt clinical treatment should be adopted to restore blood flow within an appropriate time frame [2, 3]. However, testicular detorsion can cause progressive reperfusion injury and its damage can be more serious than ischemic injury [4].The pathological process exhibits many features of ischemia reperfusion injury (IRI). A growing body of evidence suggests that testicular IRI usually causes extensive spermatogenic cell apoptosis and testicular dysfunction [5, 6].Undoubtedly, it is essential to identify the mechanism underlying testicular IRI development and determine novel effective molecular biomarkers.

According to the human genome project, only approximately $2 \%$ of DNA sequences in the human genome are protein-coding genes and the rest of the genome is not responsible for protein coding transcribed as non-coding RNAs (ncRNAs) [7]. Long non-coding RNA (lncRNA) represents a newly discovered class of ncRNAs of more than 200 nucleotides in length [8]. Recently, accumulating studies have demonstrated that IncRNAs are widely involved in various biological processes such as cell apoptosis, proliferation, differentiation and angiogenesis $[9,10]$.Moreover, they can also modulate gene expression through a variety of mechanisms, including chromatin structure remodeling, regulating cutting and splicing machinery, adjusting transcription factor activity and controlling RNA decay and epigenetics $[11,12]$. Therefore, lncRNAs may possess great potential as new therapeutic targets during the progression of IRI.

The abnormal expression of IncRNAs has been found in the progression of a variety of organ IRIs. Increasing evidence has suggested that lncRNAs may participate in diverse biological processes in different contexts [13]. For example, Zhao et al. reported that upregulated lncRNA MALAT1 functions as a pro-apoptotic regulator in myocardial IRI through the inhibition of miR-145 [14]. Yu et al. found that lncRNA PRINS contributes to inflammatory reactions in kidney IRI by regulating RANTES expression [15]. Wu et al. showed that lncRNA N1LR reduces neuronal apoptosis and enhances cell proliferation in cerebral IR by targeting Nck1 gene expression [16]. Chen et al. demonstrated that silencing of AK139328 inhibits NF- $\kappa B$ and caspase- 3 activity with activation of the Akt signaling pathway in hepatic IRI [17]. However, the biological effect of MALAT1 in testicular IRI has not been elucidated. Therefore, our study hypothesized that IncRNA MALAT1 could serve as a novel biomarker during the progression of testicular IRI.

In this study, we found that the up-regulation of MALAT1 is a characteristic molecular change in testicular IRI and that the expression of MALAT1 is positively associated with cell apoptosis and negatively correlated with cell proliferation at different reoxygenation/ reperfusion time intervals. Furthermore, we predicted and identified miR-214 as a direct downstream target of MALAT1 and demonstrated that MALAT1 played a key role in regulating IR-induced apoptosis and proliferation in vitro and in vivo. In addition, TRPV4 was identified as a direct target of miR-214 and acted as a sensor for testicular IRI. Together, these results provide a new outlook on the role of MALAT1. Additionally, lncRNA MALAT1 may be used as an effective therapeutic target for predicting apoptosis and proliferation in the treatment of testicular IRI.

\section{Materials and Methods}

\section{Experimental animals and IRI model}

Male C57BL/6J mice (8-10 weeks of age, 20-25 g) were purchased from the Hubei Center for Disease Control. Twenty-five rats were randomly divided into 5 groups with 5 rats in each group. All experimental procedures were performed in accordance with the National Institutes of Health Guide for the Care and Use of Laboratory Animals and were approved by the Animal Care and Use Committee of Wuhan University. Prior to the experiments, the mice were housed in cages maintained in a standard temperature-controlled 


\section{Cellular Physiology Cell Physiol Biochem 2018;46:802-814 \begin{tabular}{c|c|c|}
\hline DOI: 10.1159/000488738 & (c) 2018 The Author(s). Published by S. Karger AG, Basel
\end{tabular} and Biochemistry \\ online: April 06, $2018 \quad$ www.karger.com/cpb}

room $\left(22 \pm 2^{\circ} \mathrm{C}\right)$ and were subjected to alternating 12-h light/dark cycles. They also had access to food and water without restriction. In brief, the mice were anesthetized via intraperitoneal administration of $2 \%$ sodium phenobarbital $(50 \mathrm{mg} / \mathrm{kg})$ and rectal temperature was maintained at $37.0 \pm 0.5{ }^{\circ} \mathrm{C}$. The left testis was twisted 720 degrees clockwise and fixed to the skin of the scrotum with a 5/0 silk suture. After $1 \mathrm{~h}$ of ischemia, the testis was restored to the natural position to allow reperfusion for $0,4,8$ or $16 \mathrm{~h}$. Shamoperated mice underwent a scrotal incision that was sutured with 5/0 silk without additional intervention. After reperfusion, the mice were deeply anesthetized and the left testis of each rat was removed quickly for later analysis. Additionally, an adenoviral vector containing si-MALAT1 and its negative control (si-NC) ( $n=5$,each group) were injected into seminiferous tubules while the mice were under anesthesia.

\section{Cell culture and the $O G D / R$ model}

GC-1 spermatogenic cells were purchased from ATCC (American Type Culture Collection, Manassas, VA, USA) and cultured in Dulbecco's modified Eagle's medium (DMEM; GIBCO, MA, USA) mixed with 10\% fetal bovine serum (FBS) at $37^{\circ} \mathrm{C}$ with $5 \% \mathrm{CO}_{2}$ To mimic OGD/R (oxygen glucose deprivation/reoxygenation) injury in vitro, the cells were kept in an anaerobic chamber filled with $5 \% \mathrm{CO} 2$ and $95 \% \mathrm{~N} 2$ at $37{ }^{\circ} \mathrm{C}$ for $3 \mathrm{~h}$. After OGD exposure, the medium was replaced with glucose-containing DMEM under normoxic conditions for $0,6,12,24$ or $48 \mathrm{~h}$ to reoxygenate.

\section{Plasmid construction and cell transfection}

Full-length MALAT1 from GC-1 cells was amplified by RT-PCR and then cloned into a pcDNA3.1 vector (Invitrogen, USA). Recombinant adenoviruses were packaged in HEK293T cells. Forty-eight $h$ later, adenoviruses containing MALAT1, si-MALAT1 and their respective negative controls sequence were harvested and purified. The wild-type sequence of TRPV4 3'UTR containing miR-214 binding sites was also amplified from GC-1 cells. The mutant 3'UTR sequence of TRPV4 was generated using overlap extension PCR and then the full sequences were cloned into a psiCHECK-2 vector (Promega, Madison, WI, USA). Pri-miR-214, anti-miR-214 and their respective negative controls were purchased from Biossci Company (Wuhan, China). All transfections were performed using Lipofectamine 2000 (Invitrogen, Carlsbad, CA, USA) according to the manufacturer's instructions.

\section{HE staining}

After the testis tissues were fixed in $4 \%$ paraformaldehyde, they were paraffin-embedded and cut into 4- $\mu$ m sections. The sections were then stained with hematoxylin and eosin (HE) after routine procedures, including deparaffinization and hydration.

\section{TUNEL assays}

Spermatogenic cell apoptosis was evaluated using a transferase-mediated dUTP nick-end labeling (TUNEL) method with a detection kit (Roche, Mannheim, Germany) following the manufacturer's instructions. The nuclei that stained brown were considered TUNEL-positive cells. Five visual fields were randomly selected from each slide and approximately 200 cells were counted per field. The apoptosis index (AI) was determined as follows: $\mathrm{AI}=$ positive cells $/$ total cells counted) $\times 100 \%$.

\section{Quantitative Real-time PCR}

Total RNA was extracted from GC-1 cells and testis samples using TRIzol reagent (Invitrogen Life Technologies, Carlsbad, CA, USA) and the purity of RNA was examined with a DU800 UV/Vis Spectrophotometer (Beckman Coulter, CA, USA). First-strand cDNA was synthesized using a reverse transcription Reagents kit or the TaqManH MicroRNA Reverse Transcription Kit (Takara Biotechnology, Dalian China) following the manufacturer's protocol. Real-time quantitative PCR was performed using the Applied Biosystems SYBR Green mix kit and the ABI 7900 Real-Time PCR system (Applied Biosystems Life Technologies, Foster City, CA, USA). All results were normalized to the expression of GAPDH or snRNA U6. The quantitative analysis was conducted using the $2^{-\Delta \Delta \mathrm{Ct}}$ method. The primer sequences used are shown in Table 1.

\section{Cell viability}

The viability of GC-1 cells was measured by a CCK-8 cell viability test kit (Beyotime Institute of Biotechnology, Jiangsu, China). Cells were seeded in 96-well plates at a concentration of $2 \times 10^{3}$ cells/well. 


\section{Cellular Physiology Cell Physiol Biochem 2018;46:802-814 \begin{tabular}{c|c|c|c|}
\hline DOI: 10.1159/000488738 & () 2018 The Author(s). Published by S. Karger AG, Basel
\end{tabular} and Biochemistry \\ Li et al.: LncRNA MALAT1 in Testicular Ischemia-Reperfusion Injury}

Twenty-four hours after transfection, the cells were stained with $20 \mu \mathrm{L}$ of CCK8 reagent for 4 hours. Cell viability was detected according to the absorbance at $450 \mathrm{~nm}$ using a spectrophotometer (Thermo, multiskan FC, USA).

\section{Cell apoptosis}

Cell apoptosis was measured using the Annexin V-FITC/ Propidium Iodide (PI) staining kit (DOJINDO, Japan; AD10). GC-1 cells were seeded in 6-well plates at a density of $10^{6}$ cells/ mL. The cells were labeled with Annexin V-FITC for $5 \mathrm{~min}$ in the dark. Then, $5 \mathrm{mg}$ of mlPI was added to each sample for 30 min. For the statistical analysis, more than 20000 total cells per sample were measured.

\section{Western blot analysis}

Proteins from testis tissues or cultured GC-1 cells were collected using RIPA Lysis Buffer (Beyotime, Beijing, China) and quantified with a bicinchoninic acid assay (BCA) kit (Beyotime, Beijing, China). Equivalent amounts of protein samples (40 $\mu \mathrm{g} / \mathrm{lane}$ ) were separated by $10 \%$ sodium dodecyl sulfate-polyacrylamide (SDS-PAGE) gel electrophoresis and then transferred to a polyvinylidene fluoride membrane (PVDF; Billerica, MA, USA). Membranes were blocked in Tris-buffered saline (TBS) containing 5\% nonfat milk and then incubated with the following primary antibodies at $4{ }^{\circ} \mathrm{C}$ overnight: TRPV4 (ab94868; Abcam, Cambridge, UK), caspase-3 (sc7148; Santa Cruz, CA), Bax (sc493; Santa Cruz, CA) and Bcl-2 (sc7382; Santa Cruz, CA). After rinsing twice with TBST buffer, the membranes were incubated with secondary antibodies at room temperature for $1 \mathrm{~h}$. All specific bands were detected by an ECL system kit (Pierce Biotechnology, Beijing, China) and estimated by ImageJ software (NIH, Bethesda, MD, USA).

\section{Luciferase reporter assays}

MALAT1 containing the predicted miR-214 binding site was amplified by PCR and then cloned into a pmirGLO Dual-luciferase miRNA Target Expression Vector (Promega, Madison, WI, USA). To mutate the putative binding site of miR-214 in MALAT1, the sequence of the putative binding site was replaced as indicated and named as MALAT1-mutated-type (MALAT1-Mut). MALAT1-Wt or MALAT1-Mut was cotransfected with miR-214 NC or miR-214 mimics using Lipofectamine 2000 (Invitrogen, USA). After $48 \mathrm{~h}$ of transfection, luciferase activity was analyzed using a Dual-Luciferase Reporter Assay System (Promega, Madison, WI, USA). The putative and mutated miR-214 target binding sequences in TRPV4 were synthesized and cloned into luciferase reporters to form the wild-type (TRPV4-Wt) or mutated-type (TRPV4-Mut) reporter plasmids. The transfection procedure and measurement was similar as described previously.

\section{RNA immunoprecipitation assay}

An RNA immunoprecipitation assay was conducted using the EZ-Magna RIP RNA-binding protein immunoprecipitation kit (Millipore, Billerica, MA, USA) following the manufacturer's instructions. GC-1 cells were lysed by RIP lysis buffer with RNase inhibitor and subsequently incubated with RIP immunoprecipitation buffer. An antibody against argonaute2 (Ago2) (Millipore) was used to form conjugated magnetic beads. The MALAT1 fold enrichment of RNA immunoprecipitation was normalized to the RIP fraction of negative control antibody IgG (Millipore), and was subjected to qRT-PCR analysis.

\section{Immunohistochemistry}

The expressions of Bax and Bcl-2 was evaluated by immunohistochemical staining. The testis tissues were fixed in $4 \%$ paraformaldehyde, embedded in paraffin and then sliced in 4- $\mu$ m sections. The primary antibodies against Bax (sc493; Santa Cruz, CA) and Bcl-2 (sc7382; Santa Cruz, CA) were used at a dilution of 1:100. All sections were analyzed by comparing staining intensities under microscopic examination.

Statistical analysis

All data are represented as the means \pm standard deviations (SD). Differences were assessed by one-way analysis of variance (ANOVA), followed by all pairwise multiple-comparison procedures using the 


\section{Cellular Physiology Cell Physiol Biochem 2018;46:802-814

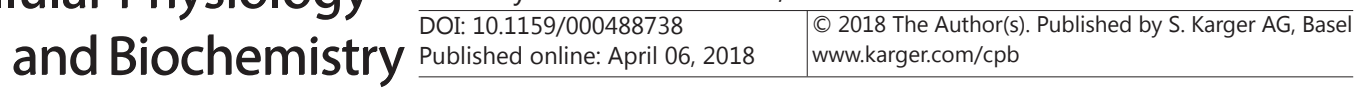 \\ Li et al.: LncRNA MALAT1 in Testicular Ischemia-Reperfusion Injury}

Bonferroni test. $\mathrm{P}<0.05$ was considered statistically significant. All experiments were performed at least 3 times. The data analysis was performed using SPSS 20.0 (SPSS, Inc., Chicago, IL, USA).

\section{Results}

IncRNA MALAT1 was involved in the response to testicular IRI and cellular OGD $/ R$

To determine the role of IncRNA MALAT1 during the progression of testicular IRI, we first established a mouse IRI model. The animal samples were examined by HE staining and TUNEL assays at $0,4,8$ or $16 \mathrm{~h}$ of reperfusion after $1 \mathrm{~h}$ of ischemia. As shown in Fig. 1A and $\mathrm{B}$, testicular spermatogenic function was significantly injured and markedly elevated during prolonged reperfusion and the apoptosis index increased gradually and peaked at $8 \mathrm{~h}$ of reperfusion compared with the sham group. These pathophysiological changes indicated successful establishment of the testicular IRI model in our study. Next, we measured the expression of MALAT1 in mice testes samples by qRT-PCR. The results showed that the level of MALAT1 abruptly increased, reaching its maximum at $1 \mathrm{~h}$ of ischemia/8 $\mathrm{h}$ of reperfusion (Fig. 1C). We further investigated MALAT1 expression in a cellular OGD/R model using mice GC-1 cells. First, data from the CCK-8 assay showed that $\mathrm{OGD} / \mathrm{R}$ reduced the viability of GC-1 cells, which continuously decreased to approximately $40 \%$ at $3 \mathrm{~h}$ of $0 \mathrm{GD} / 24 \mathrm{~h}$ of reoxygenation, with a significant difference from the normoxia group (Fig. 1D). Second, $3 \mathrm{~h}$ of OGD followed by $24 \mathrm{~h}$ of reoxygenation induced significantly higher MALAT1 expression compared with the normoxia group (Fig. 1E), which was consistent with the decrease in cell viability and was similar to the trend observed in the vivo IRI model. Collectively, these data suggested that MALAT1 may be involved in the progression of testicular IRI.

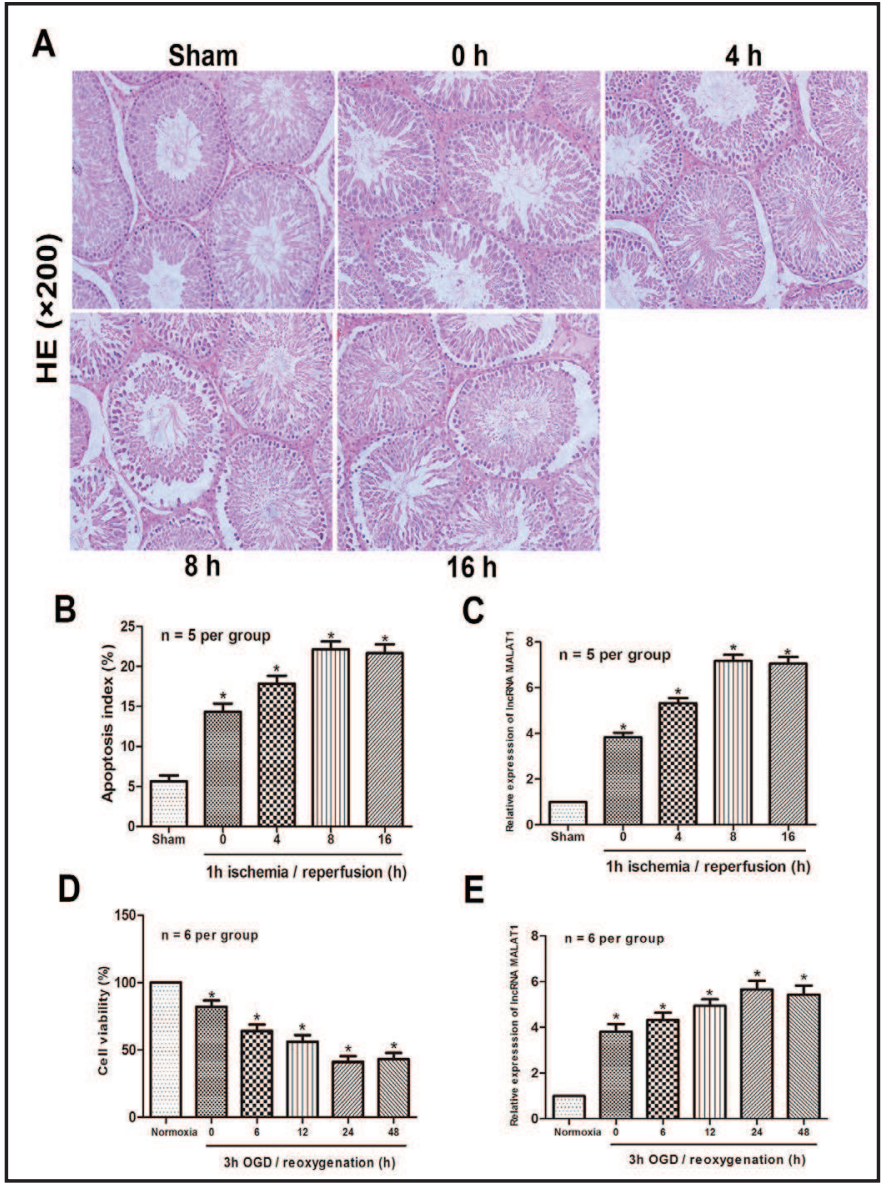

Fig. 1. IncRNA MALAT1 was involved in the response to testicular IRI and cellular OGD/R. (A) HE staining in the testes exposed to $1 \mathrm{~h}$ ischemia followed by reperfusion of different durations. $\mathrm{n}=5$ per group; (B) QRT-PCR of MALAT1 level expression at different reperfusion durations after $1 \mathrm{~h}$ ischemia in animal samples. ${ }^{*} \mathrm{p}<0.05$ vs. sham, $\mathrm{n}=5$ per group; (C) TUNEL assays were performed to investigate the cell apoptosis at $1 \mathrm{~h}$ ischemia followed by reperfusion of different durations. ${ }^{*} \mathrm{p}<0.05$ vs. sham, $\mathrm{n}=5$ per group; (D) CCK-8 assays were performed to determine cellular viability in GC-1 cells at 3 h OGD exposure followed by different reoxygenation conditions. ${ }^{*} \mathrm{p}<0.05$ vs. normoxia, $\mathrm{n}=6$ per group; (E) Relative expression level of MALAT1 in GC-1 cells under different reoxygenation conditions after $3 \mathrm{~h}$ OGD exposure. ${ }^{*} \mathrm{p}<0.05$ vs. normoxia, $\mathrm{n}=6$ per group. 


\section{Cellular Physiology Cell Physiol Biochem 2018;46:802-814 \begin{tabular}{l|l|l|l} 
DOI: 10.1159/000488738 & 2018 The Author(s). Published by S. Karger AG, Basel \\
\hline
\end{tabular}}

and Biochemistry $\frac{\text { Published onIIne: April 06, } 2018}{\text { Li et al.: LncRNA MALAT1 in Testicular Ischemia-Reperfusion Injury }}$

Influence of IncRNA MALAT1 on spermatogenic cell apoptosis and proliferation in vitro

To investigate the effect of IncRNA MALAT1 on OGD-induced cell injury, we increased the expression of MALAT1 via transfection of recombinant adenoviruses and suppressed that by small interfering RNA (siRNA) in GC-1 cells. The qRT-PCR analysis suggested that the expression of MALAT1 significantly increased in adenovirus-MALAT1-transfected cells and remarkably decreased in si-MALAT1-transfected cells at $3 \mathrm{~h}$ of OGD/24 h of reoxygenation compared with their negative controls, respectively (Fig. 2A). In addition, the results of

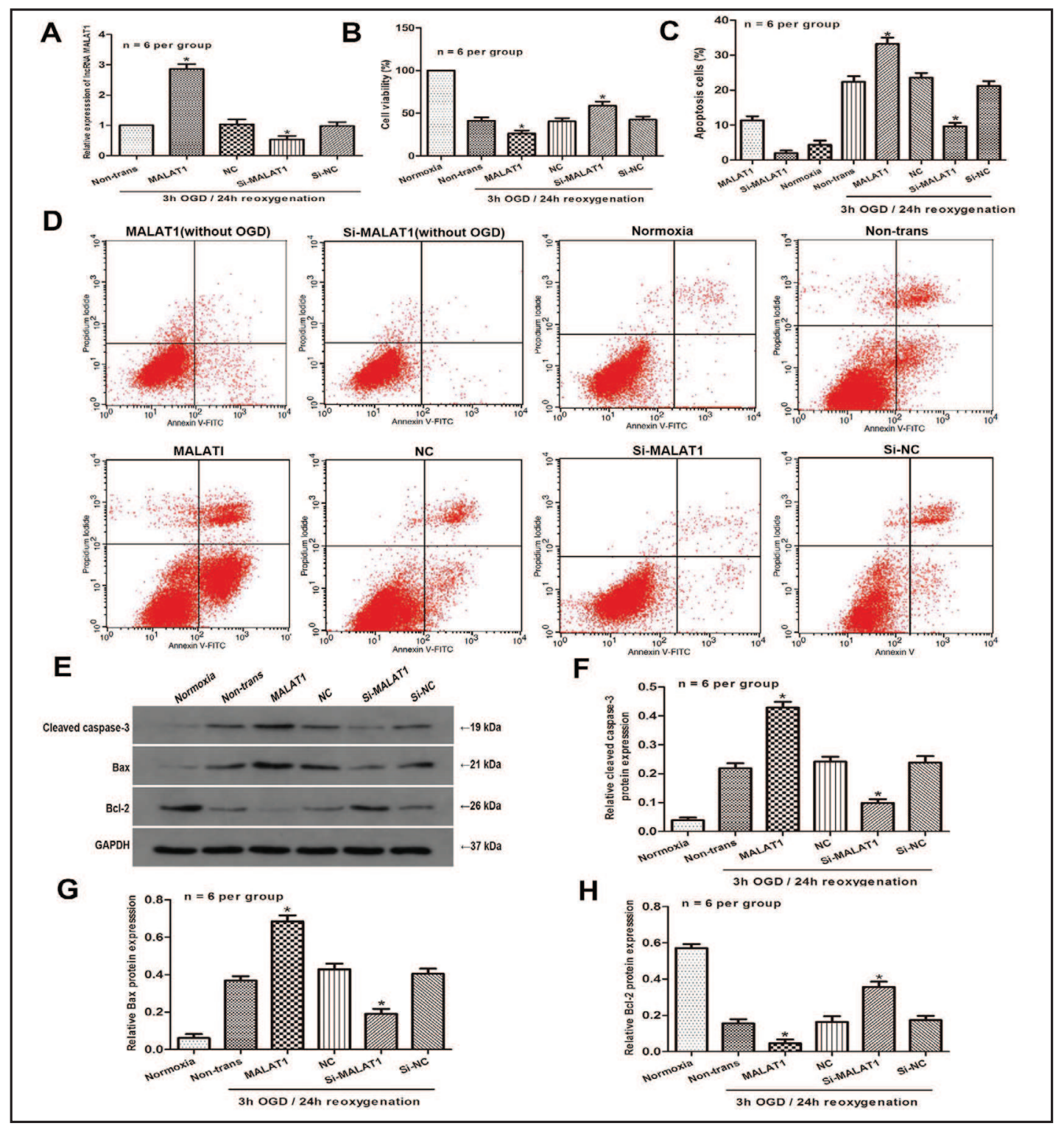

Fig. 2. Influence of IncRNA MALAT1 on spermatogenic cell apoptosis and proliferation in vitro. (A) Relative expression of MALAT1 in GC-1 cells after transfection with MALAT1 or si-MALAT1. ${ }^{*} \mathrm{p}<0.05$ vs. respective control group, $\mathrm{n}=6$ per group; (B) CCK-8 assays were performed to evaluate cellular viability in GC-1 cells transfected with MALAT1 or si-MALAT1 in normoxia and $3 \mathrm{~h}$ OGD/24 h reoxygenation treatments. ${ }^{*} \mathrm{p}<0.05$ vs. non-trans, $\mathrm{n}=6$ per group; (C,D) Cell apoptosis of GC-1 cells transfected with MALAT1 or si-MALAT1 was examined by flow cytometry in normoxia, without OGD and $3 \mathrm{~h}$ OGD/24 h reoxygenation treatments. * $\mathrm{p}<0.05$ vs. non-trans, $\mathrm{n}=6$ per group; $(\mathrm{E}-\mathrm{H})$ Cleaved caspase-3, Bax and Bcl-2 protein levels transfected with MALAT1 or si-MALAT1 were examined in normoxia and $3 \mathrm{~h}$ OGD/24 h reoxygenation treatments by western blot analysis. ${ }^{*} \mathrm{p}<0.05$ vs. non-trans, $\mathrm{n}=6$ per group. 


\section{Cellular Physiology Cell Physiol Biochem 2018;46:802-814

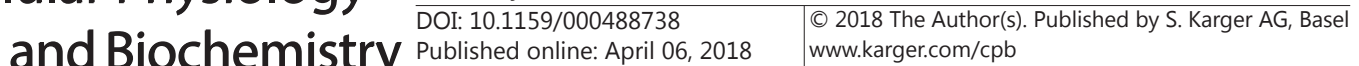 \\ Li et al.: LncRNA MALAT1 in Testicular Ischemia-Reperfusion Injury}

the CCK8 assay showed that the over-expression of MALAT1 remarkably inhibited cellular viability induced by $3 \mathrm{~h}$ of OGD/24 h of reoxygenation. However, knockdown of MALAT1 caused an opposite result (Fig. 2B). Flow cytometry data also showed that GC-1 cell apoptosis was induced by $3 \mathrm{~h}$ of OGD/24 h of reoxygenation. Our data showed that MALAT1 over-expression markedly promoted cell apoptosis, but MALAT1 knockdown significantly suppressed cell apoptosis in GC-1 cells (Fig. 2C, D). Furthermore, the western blot analysis showed that MALAT1 over-expression increased the expressions of caspase- 3 and Bax and decreased the expression of Bcl-2. Consistent with this result, the inhibition of MALAT1 in GC- 1 cells resulted in decreased caspase- 3 and Bax levels and increased Bcl-2 expression (Fig. 2E-H). Taken together, these findings indicated that the over-expression of MALAT1 promoted cell apoptosis and inhibited cell proliferation in testicular spermatogenic cells.

Fig. 3. IncRNA MALAT1 inhibits miR-214 expression by directly targeting it. (A) Relative expression level of miR214 in GC-1 cells under different reoxygenation conditions after $3 \mathrm{~h}$ OGD exposure. ${ }^{*} \mathrm{p}<0.05$ vs. normoxia, $\mathrm{n}=6$ per group; (B) A two-tailed Pearson's correlation analysis was performed to determine the relationship between miR-214 and IncRNA MALAT1 ( $<<0.05) ; \quad(C)$ qRT-PCR assays were performed to analyze the expression level of miR-214 after transfection with pri-miR-214 or anti-miR-214 in $3 \mathrm{~h}$ OGD/24 h reoxygenation treatments. $\quad * \mathrm{P}<0.05$ vs. respective control group, $\mathrm{n}=6$ per group; (D) Relative expression of MALAT1 transfected with pri-miR-214 or anti-miR-214 was deter-

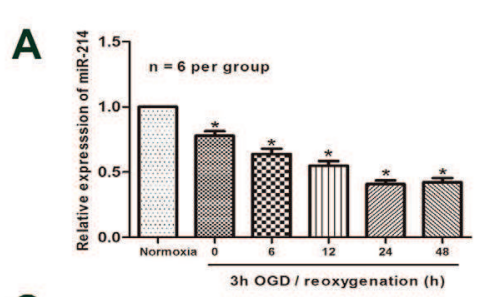

C

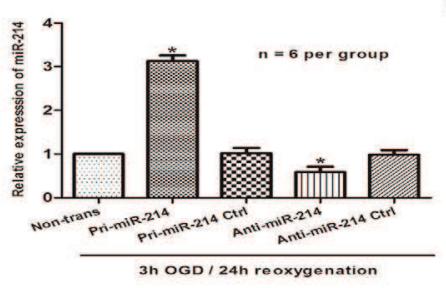

E

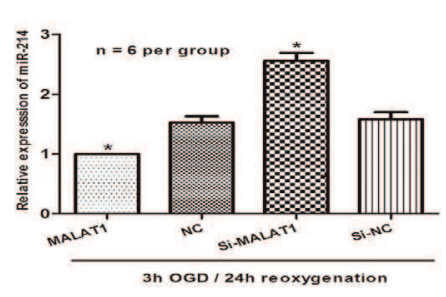

G

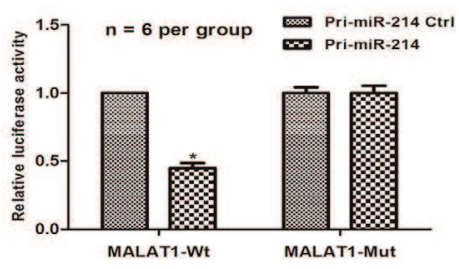

B

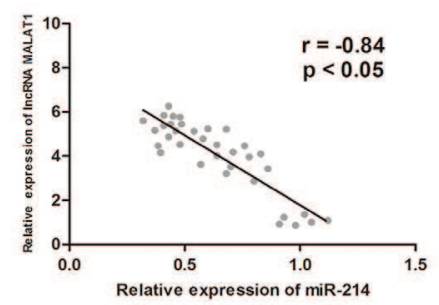

D

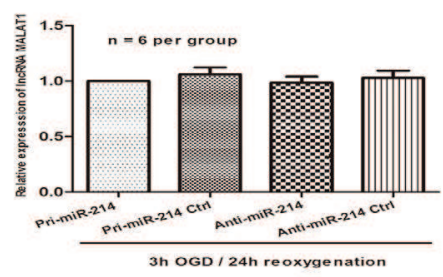

$\mathbf{F}$

IncRNA MALAT1-Wt 5'-GCAGGAAACAGCAGACUGCUGU-3' mmu-miR-214 3'-UGACGGACAGACACGGACGACA InCRNA MALAT1-Mut 5'-GCAAGAAACAGCAGAUACGCUA-3'

H

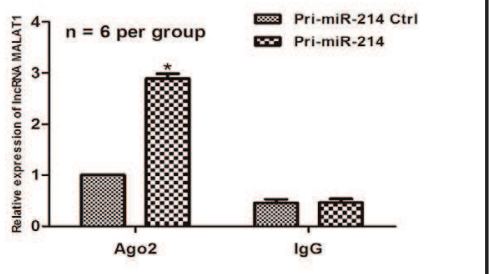
mined by qRT-PCR in $3 \mathrm{~h}$

OGD $/ 24 \mathrm{~h}$ reoxygenation treatments. ${ }^{*} \mathrm{P}<0.05$ vs. respective control group, $\mathrm{n}=6$ per group; (E) Relative expression of miR-214 transfected with MALAT1 and si-MALAT1 was examined by qRT-PCR in $3 \mathrm{~h} \mathrm{OGD/24}$ $\mathrm{h}$ reoxygenation treatments. ${ }^{*} \mathrm{P}<0.05$ vs. respective control group, $\mathrm{n}=6$ per group; (F) Putative binding site of miR-214 on MALAT1. (G) Dual-luciferase reporter assay was performed to determine luciferase activity in GC-1 cells co-transfected with pri-miR-214 and MALAT1-Wt or MALAT1-Mut. ${ }^{*} \mathrm{P}<0.05$ vs. pri-miR-214 ctrl group, $\mathrm{n}=6$ per group; (H) RNA-IP assay was performed in GC-1 cells transfected with pri-miR-214 and pri-miR-214 ctrl. The expression of MALAT1 was determined by qRT-PCR. ${ }^{*} \mathrm{P}<0.05$ vs. pri-miR-214 ctrl group, $\mathrm{n}=6$ per group. 


\section{Cellular Physiology Cell Physiol Biochem 2018;46:802-814 and Biochemistry

\section{IncRNA MALAT1 inhibits miR-214 expression by directly targeting it}

It has been elucidated that IncRNAs can competitively binding to miRNAs and function as a competing endogenous RNAs (ceRNAs), consequently modulating the depression of miRNA targets $[18,19]$. Previous studies have reported that miR-214 regulates cell proliferation and apoptosis in ovarian and nasopharyngeal cancer [20, 21]. Moreover, it has been found that miR-214 is tightly associated with the progression of myocardial IRI [22]. Therefore, we intended to delineate the interaction between IncRNA MALAT1 and miR-214 in testicular IRI. First, the qRT-PCR analysis showed that the expression of miR-214 was low in OGD-induced cell injury compared with the normoxia group (Fig. 3A), which was inversely associated with the expression of MALAT1 (Fig. 3B). Next, we transfected the GC-1 cells with pri-miR-214 and anti-miR-214 to change the miR-214 levels in GC-1 cells and a qRT-PCR analysis was performed to verify the efficiency of transfection (Fig. 3C). To further investigate whether MALAT1 was regulated by miR-214, we detected the expression level of MALAT1 in GC-1 cells transfected with pri-miR-214, anti-miR-214 and their respective negative controls. The results suggested that the over-expression of miR-214 could not reduce the expression of MALAT1 in GC-1 cells (Fig. 3D). However, the over-expression of MALAT1 significantly decreased the expression of miR-214 compared to the negative control (Fig. 3E). To validate that IncRNA MALAT1 directly binds to miR-214, we performed an in silico prediction of target sites in the sequence of miR-214 using the LncBase Experimental v.2 database (Fig. 3F). We found that miR-214 overexpression could decrease ATB-WT luciferase activity but could not affect ATB-Mut luciferase activity compared with miR-214 NC (Fig. 3G). Previous studies have demonstrated that microRNAs degrade RNA or repress translation in an Ago2-dependent manner. To further support this conclusion, we employed an anti-Ago2 RIP assay in GC-1 cells transfected with pri-miR-214. Endogenous MALAT1 was pulled down specifically in miR-214-transfected cells, suggesting that miR-214 is a direct inhibitory target of IncRNA MALAT1 (Fig. 3H). Therefore, these results demonstrated that miR-214 was an inhibitory target of MALAT1 during the progression of testicular IRI.

\section{TRPV4 is a target gene of $\mathrm{miR}-214$ and is regulated by MALAT1}

To explore the relationship between miR-214 and TRPV4, an in silico prediction was performed using open access software (TargetScan, PicTarget and miRanda). To verify the prediction, we constructed luciferase reporter plasmids containing the wild-type 3'UTR sequence of TRPV4 or the mutant 3'UTR sequence. A mutant reporter vector of 3'UTR of TRPV4 containing a luciferase reporter was used as a negative control. The data from the luciferase reporter assay showed that the over-expression of miR-214 significantly decreased the reporter vector activity of TRPV4 3'UTR in GC-1 cells, but there was no change in the TRPV4-Mut group (Fig. 4A, B). To confirm the regulation of TRPV4 by miR214, we examined the expression of TRPV4 after miR-214 over-expression or knockdown. The western blot analysis showed that miR-214 over-expression decreased the expression of TRPV4 and that miR-214 knockdown caused a significant increase in TRPV4 expression (Fig. 4C, D). To further explore whether TRPV4 and cleaved caspase-3 were regulated by MALAT1, we determined the protein expression of TRPV4 and cleaved caspase- 3 after cells were transfected with MALAT1 or si-MALAT1 and pri-miR-214 or anti-miR-214. We found that MALAT1 over-expression markedly promoted the expression of TRPV4 and cleaved caspase-3, but miR-214 abrogated this increase in TRPV4 and cleaved caspase-3 expression induced by MALAT1. On the other hand, MALAT1 knockdown led to a reduction in TRPV4 and cleaved caspase-3, which could be rescued by miR-214 inhibition (Fig. 4E-L). Therefore, these findings revealed that the regulation of TRPV4 and cleaved caspase- 3 by MALAT1 required the activity of miR-214.

IncRNA MALAT1 promotes spermatogenic cell apoptosis caused by testicular IRI in vivo

To further determine the effect of MALAT1 on spermatogenic cell apoptosis in vivo, we injected si-MALAT1 or si-NC into mouse seminiferous tubules. The transfection effect was confirmed by a qRT-PCR analysis and the expression level of MALAT1 was remarkably down- 


\section{Cellular Physiology Cell Physiol Biochem 2018;46:802-814 \begin{tabular}{c|l} 
DOI: 10.1159/000488738 & (c) 2018 The Author(s). Published by S. Karger AG, Basel \\
why Biochemistry
\end{tabular} \\ Li et al.: LncRNA MALAT1 in Testicular Ischemia-Reperfusion Injury}

Fig. 4. TRPV4 is a target gene of miR214 and is regulated by MALAT1. (A) Predicted miR-214 binding sites in the 3'UTR of TRPV4 (TRPV4$\mathrm{Wt}$ ) and its mutated sequence (TRPV4-Mut) was shown; (B) Luciferase reporter assay was performed to determine luciferase activity in GC-1 cells co-transfected with pri-miR-214 and luciferase reporters containing 3'UTR sequence of TRPV4-Wt or TRPV4-Mut. ${ }^{*} \mathrm{P}<0.05$ vs. primiR-214 ctrl group, $\mathrm{n}=6$ per group; (C,D) TRPV4 protein levels of GC-1 cells transfected with pri-miR-214 or anti-miR-214 in $3 \mathrm{~h} \mathrm{OGD/24}$
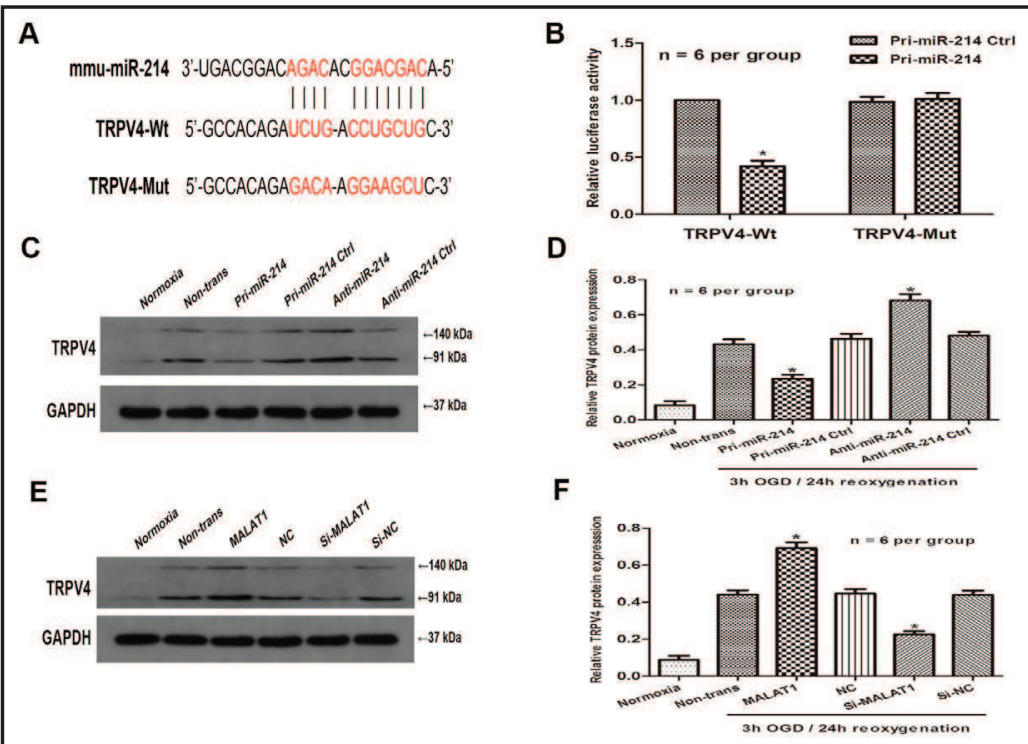

$\mathbf{G}$ nc,$\quad H$

I

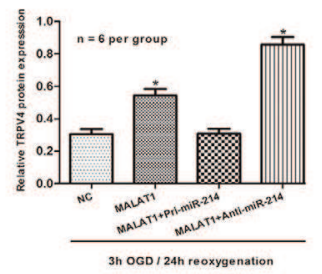

K
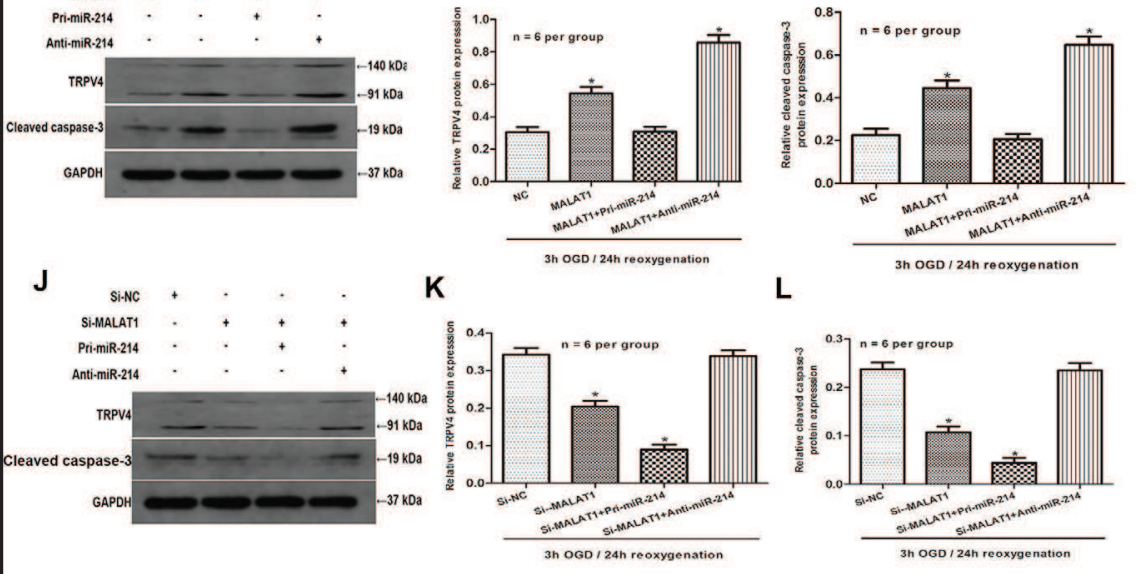

$\mathrm{h}$ reoxygenation

treatments. ${ }^{*} \mathrm{P}<0.05$ vs. non-trans, $\mathrm{n}=6$ per group; (E,F) TRPV4 protein levels of GC- 1 cells transfected with MALAT1 or si-MALAT1 in $3 \mathrm{~h} \mathrm{OGD/24} \mathrm{h}$ reoxygenation treatments. ${ }^{*} \mathrm{P}<0.05$ vs. non-trans, $\mathrm{n}=6$ per group; (G-I) Relative TRPV4 and cleaved caspase-3 protein expressions co-transfected with MALAT1 and pri-miR-214 or anti-miR-214 in 3 h OGD/24 h reoxygenation treatments. ${ }^{*} \mathrm{P}<0.05$ vs. NC group, $\mathrm{n}=6$ per group; (J-L) Relative TRPV4 and cleaved caspase-3 protein expressions co-transfected with si-MALAT1 and pri-miR-214 or anti-miR-214 in $3 \mathrm{~h} \mathrm{OGD} / 24 \mathrm{~h}$ reoxygenation treatments. ${ }^{*} \mathrm{P}<0.05$ vs. si-NC group, $\mathrm{n}=6$ per group.

regulated in si-MALAT1-transfected GC-1 cells at $1 \mathrm{~h}$ of ischemia/ $8 \mathrm{~h}$ of reperfusion compared with the negative control group (Fig. 5A). A TUNEL assay was used to investigate whether IncRNA MALAT1 could affect spermatogenic cell apoptosis in response to $1 \mathrm{~h}$ of ischemia/8 $\mathrm{h}$ of reperfusion. The results of the TUNEL assay showed that IR-induced spermatogenic cell apoptosis was significantly reduced by the injection of si-MALAT1 (Fig. 5B, C). We detected the expressions of Bax and Bcl-2 in testicular samples via immunohistochemical staining. As the results showed, the number of Bax-positive cells in the si-MALAT1 group was obviously fewer than in the negative control group, but Bcl-2 expression was moderately increased in the si-MALAT1 group compared to the negative control group (Fig. 5D). Moreover, the western blot data showed that si-MALAT1 treatment decreased the protein levels of TRPV4 and caspase-3 compared to the negative control group (Fig. 5E-G). Together, these data 


\section{Cellular Physiology Cell Physiol Biochem 2018;46:802-814 \begin{tabular}{c|l|l} 
DOI: 10.1159/000488738 & (c) 2018 The Author(s). Published by S. Karger AG, Basel \\
www Biochemistry
\end{tabular} \\ Li et al.: LncRNA MALAT1 in Testicular Ischemia-Reperfusion Injury}

Fig. 5. IncRNA MALAT1 promotes spermatogenic cell apoptosis caused by testicular IRI in vivo. (A) QRT-PCR assay was performed to analyze the relative level of MALAT1 after transfection with siMALAT1 or si-NC at 1 $\mathrm{h}$ of ischemia followed by $8 \mathrm{~h}$ of reperfusion. ${ }^{*} \mathrm{p}<0.05$ vs. none, $\mathrm{n}=5$ per group; $(\mathrm{B}, \mathrm{C})$ TUNEL assays was performed to investigate the cell apoptosis after transfection with si-MALAT1 or si-NC at $8 \mathrm{~h}$ of reperfusion after $1 \mathrm{~h}$ ischemia. ${ }^{*} \mathrm{p}<0.05$ vs. none, $\mathrm{n}=5$ per group; (D) Immunohistoch emistry staining of Bax and Bcl-2 after transfection with si-MALAT1 or si$\mathrm{NC}$ at $1 \mathrm{~h}$ of ischemia/8 $\mathrm{h}$ of reperfusion. $\mathrm{n}=5$

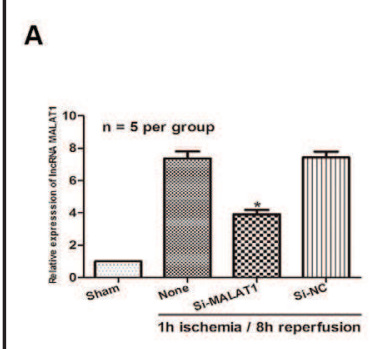

B

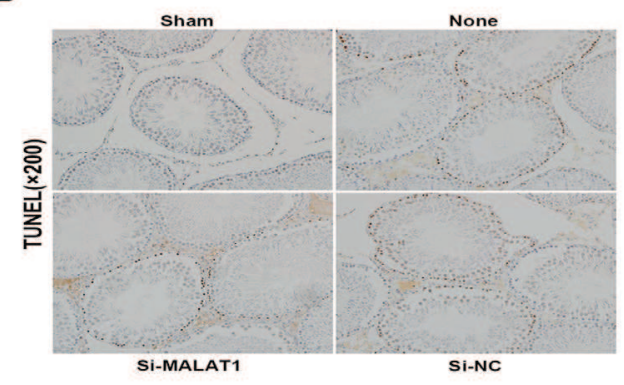

C

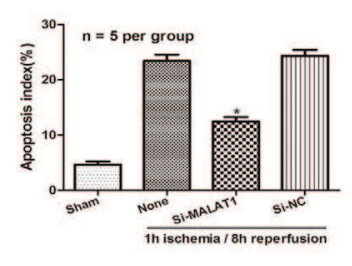

D

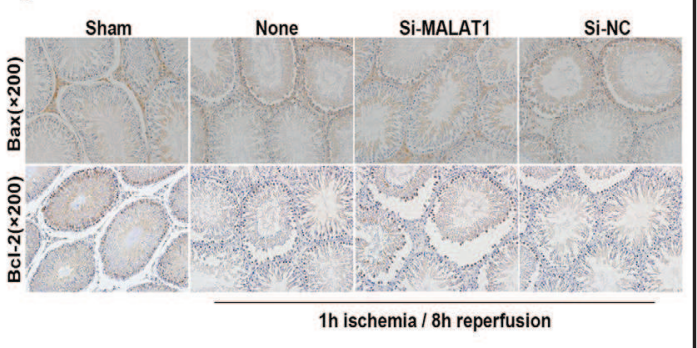

E

F

G

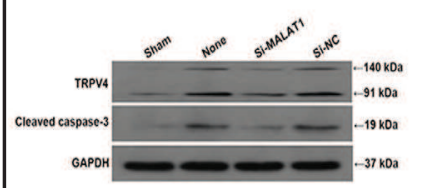

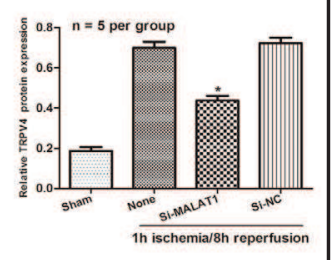
per group; (E-G) TRPV4

and cleaved caspase-3 protein levels expression after transfection with si-MALAT1 or si-NC were detected at $1 \mathrm{~h}$ of ischemia followed by $8 \mathrm{~h}$ of reperfusion by western blot analysis. ${ }^{*} \mathrm{p}<0.05$ vs. none, $\mathrm{n}=5$ per group.

suggested that IncRNA MALAT1 could promote spermatogenic cell apoptosis in testicular IRI in vivo.

\section{Discussion}

The pathophysiological mechanisms of testicular T/D center around testicular IRI, in which torsion results in ischemic damage and detorsion leads to enhanced blood flow and subsequent reperfusion injury, resulting in spermatogenic cell apoptosis and the disruption of spermatogenesis, eventually leading to testicular dysfunction and infertility [23, 24]. The two major factors affecting testicular damage are the duration and degree of spermatic cord torsion, with testicular salvage rates from manipulative and operative reduction ranging from $42 \%$ to $88 \%[25,26]$. Due to the fast development of basic medical research, the molecular mechanisms underlying the pathogenesis of testicular IRI have emerged gradually over the past few years. Extensive research has indicated that the dysregulation of IncRNAs may contribute to IRI progression in many systems [27-29]. Therefore, elucidating the role and biological functions of IncRNAs in testicular IRI is critical to better identify diagnostic tools and treatments in clinical settings.

MALAT1 is an 8-Kb nuclear-residing lncRNA that is capable of interacting with serine/ arginine(SR) proteins and influencing their cellular levels in a phosphorylation-dependent manner [30]. It was initially identified to control tumor metastasis and cancer cell survival and plays an important role in endothelial cell function and dysfunction [31]. Recent 


\section{Cellular Physiology Cell Physiol Biochem 2018;46:802-814 and Biochemistry Publisned online: April Ub, $2018 \quad \begin{aligned} & \text { D 2018 The Author(s. } \\ & \text { www.karger.com/cpb }\end{aligned}$ \\ Li et al.: LncRNA MALAT1 in Testicular Ischemia-Reperfusion Injury}

studies have demonstrated that MALAT1 was aberrantly expressed in several pathological processes, including gastric cancer, colorectal cancer myocardial IRI and cerebral IRI [14, 3234]. In the current study, we found that the expression of MALAT1 in testicular IR tissues was remarkably increased compared with normal tissues. High MALAT1 expression levels were positively associated with cell apoptosis and negatively correlated with cell proliferation in vitro and in vivo. Furthermore, in gain and loss of function assays, we verified that the overexpression of MALAT1 induced significant suppression of cell proliferation. On the other hand, knockdown of MALAT1 led to an inverse result. These data suggest that lncRNA MALAT1 may exert regulatory effects on apoptosis and proliferation in testicular IRI.

Emerging evidence has reported that IncRNAs may act as competing endogenous RNAs (ceRNAs) and regulate the derepression of miRNA target genes at the post-transcriptional level $[18,19] .0 n$ the basis of this theory, IncRNAs can antagonize the inhibitory ability of miRNA by competitively binding to it. For example, IncRNA XIST inhibited neuronal apoptosis by targeting miR-494 in a rat spinal cord injury model [35] and lncRNA H19 contributed to intestinal epithelial barrier function by epigenetically repressing miR-675 [36]. IncRNA MALAT1 promoted cardiomyocyte apoptosis in myocardial IRI by down-regulating miR145 [14]. In the present study, we confirmed that miR-214 expression is significantly downregulated in the progression of testicular IRI and inversely associated with the expression of MALAT1. Using bioinformatics predictions, we found that miR-214 may serve as a direct downstream target of MALAT1. To verify whether MALAT1 directly binds to miR-214, luciferase reporter assays and an RNA pull down assay were performed. Furthermore, we identified the direct binding site between MALAT1 and miR-214. Taken together, these data provide evidence that MALAT1 regulates miR-214 expression by directly targeting it.

Transient Receptor Potential Vanilloid 4 (TRPV4) is a non-selective cation channel that belongs to the transient receptor potential (TRP) family [37]. TRPV4 has been found to be involved in the regulation of various cellular activities and is widely expressed in the kidneys, brain, lungs, heart, liver and testes $[38,39]$. It has also been reported that excessive activation of this channel may be correlated with myocardial, lung and cerebral IRIs. For example, Dong et al. showed that TRPV4 inhibition alleviates myocardial IRI by reducing infarct size and apoptosis [40]. Jie et al. found that TRPV4 activation promotes cell apoptosis by regulating the PI3K/Akt and p38 MAPK signaling pathways in cerebral IRI [41]. A recent study suggested that an increase in TRPV4 is related to neurological injury, which may contribute to the activation of $\mathrm{Ca} 2^{+}$-dependent signaling pathways [42]. However, the relationship between IncRNA and TRPV4 in testicular IRI has not been elucidated. In our studies, we identified that MALAT1 could positively regulate the expression of TRPV4 post-transcriptionally by targeting miR-214 in testicular spermatogenic cells. In contrast, miR-214 overexpression did not change the expression level of MALAT1, but abolished the up-regulation of TRPV4 induced by MALAT1 overexpression. Collectively, these results suggested that lncRNA MALAT1 could function as a ceRNA and that this positive regulatory effect of MALAT1 on TRPV4 required the inhibition of miR-214.

\section{Conclusion}

In conclusion, our study demonstrated that IncRNA MALAT1 was remarkably increased during the progression of testicular IRI, which played a key role in regulating testicular spermatogenic cell apoptosis and proliferation in vitro and in vivo. In addition, we revealed that IncRNA MALAT1 positively regulated TRPV4 expression at the post-transcription level by directly targeting miR-214 in testicular IRI. Therefore, our study indicated that lncRNA MALAT1 could potentially serve as a novel biomarker in the treatment of testicular IRI.

\section{Disclosure Statement}

No conflict of interest exists. 


\section{Cellular Physiology \\ Cell Physiol Biochem 2018;46:802-814 and Biochemistry

\section{References}

-1 Ahmed AI, Lasheen NN, El-Zawahry KM: Ginkgo biloba ameliorates subfertility induced by testicular Ischemia/Reperfusion injury in adult wistar rats: A possible new mitochondrial mechanism. Oxid Med Cell Longev 2016;2016:6959274.

-2 Kim HJ, Lee JW, Hwang BR, Lee YA, Kim JI, Cho YJ, Jhun HJ, Han JS: Protective effect of pterostilbene on testicular ischemia/reperfusion injury in rats. J Pediatr Surg 2016;51:1192-1196.

- 3 Al-Maghrebi M, Renno WM: Altered expression profile of glycolytic enzymes during testicular ischemia reperfusion injury is associated with the p53/TIGAR pathway: Effect of fructose 1, 6-diphosphate. Peerj 2016;4:e2195.

-4 Shimizu S, Tsounapi P, Dimitriadis F, Higashi Y, Shimizu T, Saito M: Testicular torsion-detorsion and potential therapeutic treatments: A possible role for ischemic postconditioning. Int J Urol 2016;23:454463.

5 Mestrovic J, Drmic-Hofman I, Pogorelic Z, Vilovic K, Supe-Domic D, Seselja-Perisin A, Capkun V: Beneficial effect of nifedipine on testicular torsion-detorsion injury in rats. Urology 2014;84:1194-1198.

6 Lysiak JJ, Nguyen QA, Kirby JL, Turner TT: Ischemia-reperfusion of the murine testis stimulates the expression of proinflammatory cytokines and activation of c-jun $\mathrm{N}$-terminal kinase in a pathway to E-selectin expression. Biol Reprod 2003;69:202-210.

-7 Djebali S, Davis CA, Merkel A, Dobin A, Lassmann T, Mortazavi A, Tanzer A, Lagarde J, Lin W, Schlesinger F, Xue C, Marinov GK, Khatun J, Williams BA, Zaleski C, Rozowsky J, Roder M, Kokocinski F, Abdelhamid RF, Alioto T, Antoshechkin I, Baer MT, Bar NS, Batut P, Bell K, Bell I, Chakrabortty S, Chen X, Chrast J, Curado J, Derrien T, Drenkow J, Dumais E, Dumais J, Duttagupta R, Falconnet E, Fastuca M, Fejes-Toth K, Ferreira P, Foissac S, Fullwood MJ, Gao H, Gonzalez D, Gordon A, Gunawardena H, Howald C, Jha S, Johnson R, Kapranov P, King B, Kingswood C, Luo OJ, Park E, Persaud K, Preall JB, Ribeca P, Risk B, Robyr D, Sammeth M, Schaffer L, See LH, Shahab A, Skancke J, Suzuki AM, Takahashi H, Tilgner H, Trout D, Walters N, Wang H, Wrobel J, Yu Y, Ruan X, Hayashizaki Y, Harrow J, Gerstein M, Hubbard T, Reymond A, Antonarakis SE, Hannon G, Giddings MC, Ruan Y, Wold B, Carninci P, Guigo R, Gingeras TR: Landscape of transcription in human cells. Nature 2012;489:101-108.

$\checkmark 8$ Martianov I, Ramadass A, Serra BA, Chow N, Akoulitchev A: Repression of the human dihydrofolate reductase gene by a non-coding interfering transcript. Nature 2007;445:666-670.

-9 Yang F, Bi J, Xue X, Zheng L, Zhi K, Hua J, Fang G: Up-regulated long non-coding RNA H19 contributes to proliferation of gastric cancer cells. Febs J 2012;279:3159-3165.

10 Carpenter S, Aiello D, Atianand MK, Ricci EP, Gandhi P, Hall LL, Byron M, Monks B, Henry-Bezy M, Lawrence JB, O’Neill LA, Moore MJ, Caffrey DR, Fitzgerald KA: A long noncoding RNA mediates both activation and repression of immune response genes. Science 2013;341:789-792.

11 Patil VS, Zhou R, Rana TM: Gene regulation by non-coding RNAs. Crit Rev Biochem Mol Biol 2014;49:16-32.

12 Mercer TR, Mattick JS: Structure and function of long noncoding RNAs in epigenetic regulation. Nat Struct Mol Biol 2013;20:300-307.

-13 Gazzaniga FS, Blackburn EH: An antiapoptotic role for telomerase RNA in human immune cells independent of telomere integrity or telomerase enzymatic activity. Blood 2014;124:3675-3684.

- 14 Zhao ZH, Hao W, Meng QT, Du XB, Lei SQ Xia ZY: Long non-coding RNA MALAT1 functions as a mediator in cardioprotective effects of fentanyl in myocardial ischemia-reperfusion injury. Cell Biol Int 2017;41:62-70.

-15 Yu TM, Palanisamy K, Sun KT, Day YJ, Shu KH, Wang IK, Shyu WC, Chen P, Chen YL, Li CY: RANTES mediates kidney ischemia reperfusion injury through a possible role of HIF-1alpha and LncRNA PRINS. Sci Rep 2016;6:18424.

- 16 Wu Z, Wu P, Zuo X, Yu N, Qin Y, Xu Q, He S, Cen B, Liao W, Ji A: LncRNA-N1LR enhances neuroprotection against ischemic stroke probably by inhibiting p53 phosphorylation. Mol Neurobiol 2016

17 Chen Z, Jia S, Li D, Cai J, Tu J, Geng B, Guan Y, Cui Q, Yang J: Silencing of long noncoding RNA AK139328 attenuates ischemia/reperfusion injury in mouse livers. Plos One 2013;8:e80817.

18 Shi X, Sun M, Liu H, Yao Y, Song Y: Long non-coding RNAs: A new frontier in the study of human diseases. Cancer Lett 2013;339:159-166.

19 Kartha RV, Subramanian S: Competing endogenous RNAs (ceRNAs): New entrants to the intricacies of gene regulation. Front Genet 2014;5:8.

-20 Liu J, Chen W, Zhang H, Liu T, Zhao L: MiR-214 targets the PTEN-mediated PI3K/Akt signaling pathway and regulates cell proliferation and apoptosis in ovarian cancer. Oncol Lett 2017;14:5711-5718.

- 21 Zhang ZC, Li YY, Wang HY, Fu S, Wang XP, Zeng MS, Zeng YX, Shao JY: Knockdown of miR-214 promotes apoptosis and inhibits cell proliferation in nasopharyngeal carcinoma. Plos One 2014;9:e86149.

22 Liu PY, Tian Y, Xu SY: Mediated protective effect of electroacupuncture pretreatment by miR-214 on myocardial ischemia/reperfusion injury. J Geriatr Cardiol 2014;11:303-310. 


\section{Cellular Physiology Cell Physiol Biochem 2018;46:802-814 \begin{tabular}{l|l|l} 
DOI: 10.1159/000488738 & (c) 2018 The Author(s). Published by S. Karger AG, Base \\
\hline
\end{tabular}

23 Chi KK, Zhang WH, Chen Z, Cui Y, He W, Wang SG, Zhang C, Chen J, Wang GC: Comparison of quercetin and resveratrol in the prevention of injury due to testicular torsion/detorsion in rats. Asian J Androl 2016;18:908-912.

24 Huang KH, Weng TI, Huang HY, Huang KD, Lin WC, Chen SC, Liu SH: Honokiol attenuates torsion/detorsioninduced testicular injury in rat testis by way of suppressing endoplasmic reticulum stress-related apoptosis. Urology 2012;79:965-967.

-25 Cvetkovic T, Stankovic J, Najman S, Pavlovic D, Stokanovic D, Vlajkovic S, Dakovic-Bjelakovic M, Cukuranovic J, Zivkovic V, Stefanovic V: Oxidant and antioxidant status in experimental rat testis after testicular torsion/ detorsion. Int J Fertil Steril 2015;9:121-128.

-26 Skondras I, Lambropoulou M, Tsaroucha A, Gardikis S, Tripsianis G, Simopoulos C, Vaos G: The role of Apigenin in testicular damage in experimental ischemia-reperfusion injury in rats. Hippokratia 2015;19:225-230.

-27 Liu Y, Li G, Lu H, Li W, Li X, Liu H, Li X, Li T, Yu B: Expression profiling and ontology analysis of long noncoding RNAs in post-ischemic heart and their implied roles in ischemia/reperfusion injury. Gene 2014;543:15-21.

28 Xu Q, Deng F, Xing Z, Wu Z, Cen B, Xu S, Zhao Z, Nepomuceno R, Bhuiyan MI, Sun D, Wang QJ, Ji A: Long non-coding RNA C2dat1 regulates CaMKIIdelta expression to promote neuronal survival through the NFkappaB signaling pathway following cerebral ischemia. Cell Death Dis 2016;7:e2173.

29 Chen Z, Luo Y, Yang W, Ding L, Wang J, Tu J, Geng B, Cui Q Yang J: Comparison analysis of dysregulated LncRNA profile in mouse plasma and liver after hepatic Ischemia/Reperfusion injury. Plos One 2015;10:e133462.

-30 Tripathi V, Ellis JD, Shen Z, Song DY, Pan Q Watt AT, Freier SM, Bennett CF, Sharma A, Bubulya PA, Blencowe BJ, Prasanth SG, Prasanth KV: The nuclear-retained noncoding RNA MALAT1 regulates alternative splicing by modulating SR splicing factor phosphorylation. Mol Cell 2010;39:925-938.

- 31 Michalik KM, You X, Manavski Y, Doddaballapur A, Zornig M, Braun T, John D, Ponomareva Y, Chen W, Uchida S, Boon RA, Dimmeler S: Long noncoding RNA MALAT1 regulates endothelial cell function and vessel growth. Circ Res 2014;114:1389-1397.

32 Lee NK, Lee JH, Ivan C, Ling H, Zhang X, Park CH, Calin GA, Lee SK: MALAT1 promoted invasiveness of gastric adenocarcinoma. BMC Cancer 2017;17:46.

33 Li P, Zhang X, Wang H, Wang L, Liu T, Du L, Yang Y, Wang C: MALAT1 is associated with poor response to Oxaliplatin-Based chemotherapy in colorectal cancer patients and promotes chemoresistance through EZH2. Mol Cancer Ther 2017;16:739-751.

$34 \mathrm{Li} \mathrm{Z,} \mathrm{Li} \mathrm{J,} \mathrm{Tang} \mathrm{N:} \mathrm{Long} \mathrm{noncoding} \mathrm{RNA} \mathrm{Malat1} \mathrm{is} \mathrm{a} \mathrm{potent} \mathrm{autophagy} \mathrm{inducer} \mathrm{protecting} \mathrm{brain} \mathrm{microvascular}$ endothelial cells against oxygen-glucose deprivation/reoxygenation-induced injury by sponging miR-26b and upregulating ULK2 expression. Neuroscience 2017;354:1-10.

35 Gu S, Xie R, Liu X, Shou J, Gu W, Che X: Long coding RNA XIST contributes to neuronal apoptosis through the downregulation of AKT phosphorylation and is negatively regulated by miR-494 in rat spinal cord injury. Int J Mol Sci 2017;18

36 Zou T, Jaladanki SK, Liu L, Xiao L, Chung HK, Wang JY, Xu Y, Gorospe M, Wang JY: H19 Long Noncoding RNA Regulates Intestinal Epithelial Barrier Function via MicroRNA 675 by Interacting with RNA-Binding Protein HuR. Mol Cell Biol 2016;36:1332-1341.

37 Fusi C, Materazzi S, Minocci D, Maio V, Oranges T, Massi D, Nassini R: Transient receptor potential vanilloid 4 (TRPV4) is downregulated in keratinocytes in human non-melanoma skin cancer. J Invest Dermatol 2014;134:2408-2417.

38 Wei ZL, Nguyen MT, O’Mahony DJ, Acevedo A, Zipfel S, Zhang Q Liu L, Dourado M, Chi C, Yip V, DeFalco J, Gustafson A, Emerling DE, Kelly MG, Kincaid J, Vincent F, Duncton MA: Identification of orally-bioavailable antagonists of the TRPV4 ion-channel. Bioorg Med Chem Lett 2015;25:4011-4015.

39 Xu ZP, Gao WC, Wang HP, Wang XH: [Expression of transient receptor potential subfamily mRNAs in rat testes]. Nan Fang Yi Ke Da Xue Xue Bao 2009;29:519-520.

40 Dong Q Li J, Wu QF, Zhao N, Qian C, Ding D, Wang BB, Chen L, Guo KF, Fu D, Han B, Liao YH, Du YM: Blockage of transient receptor potential vanilloid 4 alleviates myocardial ischemia/reperfusion injury in mice. Sci Rep 2017;7:42678.

41 Jie P, Hong Z, Tian Y, Li Y, Lin L, Zhou L, Du Y, Chen L, Chen L: Activation of transient receptor potential vanilloid 4 induces apoptosis in hippocampus through downregulating PI3K/Akt and upregulating p38 MAPK signaling pathways. Cell Death DIS 2015;6:e1775.

-42 Ryskamp DA, Witkovsky P, Barabas P, Huang W, Koehler C, Akimov NP, Lee SH, Chauhan S, Xing W, Renteria RC, Liedtke W, Krizaj D: The polymodal ion channel transient receptor potential vanilloid 4 modulates calcium flux, spiking rate, and apoptosis of mouse retinal ganglion cells. J Neurosci 2011;31:7089-7101. 